\title{
Hubungan Anemia pada Ibu Hamil dengan Kejadian Persalinan Prematur di RSUP Prof Dr. R. D. Kandou Manado
}

\author{
${ }^{1}$ Florensia S. Larumpaa \\ ${ }^{2}$ Erna Suparman \\ ${ }^{2}$ Rudy Lengkong
}

\author{
${ }^{1}$ Kandidat Skripsi Fakultas Kedokteran Universitas Sam Ratulangi Manado \\ ${ }^{2}$ Bagian Obstetri dan Ginekologi Fakultas Kedokteran Universitas Sam Ratulangi Manado \\ Email: florensiasarilarumpaa@yahoo.co.id
}

\begin{abstract}
Preterm labor is a labor that occurs at $20-<37$ weeks of gestational age calculated from the first day of the last menstrual. Until now the mortality and morbidity of preterm labor is still high. This matter is related with the maturity of the organs in the newborn such as lungs, brain and gastrointestinal tract. There are several factors that cause preterm labor inter alia maternal factor. Pregnant women with anemia potentially have preterm labors. World Health Organization (WHO) estimates that 35-37\% of pregnant women in developing countries are anemic during pregnancy. In pregnant women it is important to meet iron needs during pregnancy by supplementation of iron and folic acid. The aim of this study was to determine the correlation between anemia in pregnant women and preterm labor. This was an analytical observational study with a cross-sectional design. Samples were mothers delivered in Obstetrics and Gynecology department at Prof. Dr. R. D. Kandou General Hospital Manado from September until November 2015. The results showed correlation between anemia in pregnant women with preterm labor from 168 samples that met the inclusion criteria ( $p$ value $=0.000$ ). Conclusion: There was a significant correlation between anemia in pregnant women and preterm labor.
\end{abstract}

Keywords: anemia, preterm labor, pregnant women

\begin{abstract}
Abstrak: Persalinan prematur adalah persalinan yang terjadi antara usia kehamilan $20-<37$ minggu dihitung dari hari pertama haid terakhir. Sampai saat ini mortalitas dan morbiditas persalinan prematur masih sangat tinggi. Hal ini berkaitan dengan maturitas organ pada bayi baru lahir seperti paru, otak, dan gastrointestinal. Beberapa faktor dapat menyebabkan terjadinya persalinan prematur diantaranya faktor ibu, dimana ibu hamil dengan anemia berpotensi mengalami persalinan prematur. World Health Organization memperkiran bahwa 35-37\% ibu hamil di negara berkembang mengalami anemia selama kehamilannya. Pada ibu hamil penting untuk memenuhi kebutuhan zat besi selama kehamilan dengan suplementasi zat besi dan asam folat. Penelitian ini bertujuan untuk mengetahui hubungan antara anemia pada ibu hamil dengan kejadian persalinan prematur. Jenis penelitian ialah analitik observasional dengan desain potong lintang. Sampel penelitian yaitu ibu yang bersalin di Bagian Obstetri dan Ginekologi RSUP Prof. Dr. R. D. Kandou Manado pada bulan September hingga November 2015. Hasil penelitian dari 168 sampel ibu bersalin yang memenuhi kriteria inklusi menunjukkan terdapat hubungan bermakna antara anemia pada ibu hamil dengan kejadian persalinan prematur $(p=0,000)$. Simpulan: Terdapat hubungan bermakna antara anemia pada ibu hamil dengan kejadian persalinan prematur.
\end{abstract}

Kata kunci: anemia, persalinan prematur, ibu hamil

Menurut World Health Organization

(WHO) Persalinan prematur adalah

persalinan yang terjadi antara usia kehamilan 20-<37 minggu dihitung dari hari pertama haid terakhir pada siklus 28 hari. ${ }^{1}$ Sampai saat ini mortalitas dan 
morbiditas masih sangat tinggi. Hal ini berkaitan dengan maturitas organ pada bayi baru lahir seperti paru, otak dan gastrointestinal. Di negara barat sampai $80 \%$ dari kematian neonatus adalah akibat prematuritas dan pada bayi yang selamat $10 \%$ mengalami permasalahan dalam jangka panjang. $^{2}$

Angka kejadian persalinan prematur pada umumnya adalah sekitar 6-10\%. Diperkirakan terdapat 12.870 persalinan prematur per 1000 persalinan di seluruh dunia $(9,6 \%)$, di Asia kelahiran prematur sebanyak 6.907 per 1000 kelahiran $(9,1 \%)$, sedangkan di Asia tenggara terdapat 1.271 kelahiran prematur per 1000 kelahiran $(11,1 \%)^{3} \quad$ Angka kejadian persalinan prematur di Indonesia pada tahun 1983 yaitu sebesar $18,5 \%$ dan pada tahun 1995 menurun menjadi 14,2\%. Pada tahun 2005 angka persalinan prematur di Indonesia sebesar $10 \% .^{4}$

Beberapa faktor mempunyai andil dalam terjadinya persalinan prematur seperti faktor pada Ibu, faktor pada janin dan plasenta, ataupun faktor lain seperti sosioekonomik. ${ }^{5}$ Ibu hamil dengan gizi kurang dan anemia juga berpotensi mengalami persalinan prematur. Akan tetapi hubungan antara anemia pada Ibu hamil dengan persalinan prematur masih belum jelas. ${ }^{6}$ World Health Organization (WHO) memperkirakan bahwa 35-37\% Ibu hamil di negara berkembang dan $18 \%$ Ibu hamil di negara maju mengalami anemia. ${ }^{7}$

Hasil penelitian oleh Irmawati $^{8}$ menunjukkan bahwa Ibu hamil dengan anemia berisiko sebesar 4,38 kali untuk melahirkan prematur dibandingkan dengan Ibu yang tidak anemia selama kehamilannya. Hasil penelitian hubungan anemia terhadap persalinan prematur di RSUD Dr. Moewadi Surakarta diperoleh nilai $p=0,001$ dimana terdapat pengaruh anemia terhadap persalinan prematur. ${ }^{9}$

Berdasarkan uraian tersebut, peneliti tertarik untuk mengetahui hubungan antara anemia pada ibu hamil dengan kejadian persalinan prematur di Bagian Obstetri dan Ginekologi RSUP Prof. Dr. R. D. Kandou Manado.

\section{METODE PENELITIAN}

Penelitian ini merupakan studi crosssectional dengan metode analisisobservasional. Penelitian dilakukan di Bagian Obstetri dan Ginekologi RSUP Prof. Dr. R. D. Kandou Manado pada bulan Oktober hingga November 2016. Sampel penelitian adalah semua ibu yang bersalin di Bagian Obstetri dan Ginekologi RSUP Prof. Dr. R. D. Kandou Manado pada bulan September - November 2016. Variabel bebas dalam penelitian ini adalah ibu dengan riwayat anemia selama kehamilan, sedangkan variabel terikat adalah kejadian Persalinan Prematur. Jenis data yang digunakan adalah data sekunder berupa data rekam medis ibu bersalin. Selanjutnya, data dianalisa menggunakan SPSS versi 20.0 .

\section{HASIL PENELITIAN}

Berdasarkan hasil penelitian, didapatkan 168 sampel yang memenuhi kriteria inklusi dari 308 jumlah kasus persalinan di Bagian Obstetri dan Ginekologi RSUP Prof. Dr. R. D. Kandou Manado pada bulan September November 2016.

Tabel 1. Karakteristik sampel ibu

\begin{tabular}{lcc}
\hline Karakteristik & $\mathbf{N}$ & $\mathbf{\%}$ \\
\hline Usia Ibu & & \\
$\leq 20$ & 25 & 14,9 \\
$21-34$ & 104 & 61,9 \\
$\geq 35$ & 39 & 23,2 \\
Pendidikan & & \\
Rendah & 21 & 12,5 \\
Menengah & 132 & 78,6 \\
Tinggi & 15 & 8,9 \\
Pekerjaan & & \\
IRT & 148 & 88,1 \\
PNS & 9 & 5,4 \\
Swasta & 9 & 5,4 \\
Wiraswasta & 2 & 1,2 \\
ANC & & \\
$\quad<4$ & 49 & 29,2 \\
$\geq 4$ & 119 & 70,8 \\
\hline
\end{tabular}

Tabel 1 didapatkan usia ibu sebagian besar berada pada usia 21-34 tahun sebanyak 104 orang $(61,9 \%)$. Berdasarkan pendidikan ibu, yang terbanyak berada 
pada tingkat pendidikan mengengah yaitu 132 orang $(78,6 \%)$. Berdasarkan pekerjaan ibu, yang terbanyak merupakan Ibu Rumah Tangga (IRT) sebanyak 148 orang $(88,1 \%)$. Dan berdasarkan pemeriksaan ANC yang terbanyak adalah ibu dengan ANC $>4$ kali yaitu 119 orang $(70,2 \%)$.

Tabel 2. Distribusi anemia pada ibu hamil

\begin{tabular}{ccc}
\hline Anemia & N & \% \\
\hline Tidak Anemia & 115 & 68,5 \\
Anemia Ringan & 22 & 13,1 \\
Anemia Sedang & 30 & 17,9 \\
Anemia Berat & 1 & 0,6 \\
Jumlah & 168 & 100,0 \\
\hline
\end{tabular}

Tabel 2 menunjukkan distribusi berdasarkan anemia pada ibu hamil yang terbanyak adalah yang tidak mengalami anemia yaitu 115 orang $(68,5 \%)$.

Tabel 3. Distribusi persalinan prematur

\begin{tabular}{ccc}
\hline Persalinan prematur & N & \% \\
\hline Ya & 37 & 22,0 \\
Tidak & 131 & 78,0 \\
Jumlah & 168 & 100,0 \\
\hline
\end{tabular}

Tabel 3 menunjukkan distribusi berdasarkan persalinan prematur yang terbanyak adalah ibu dengan persalinan aterm yaitu 131 orang $(78,0 \%)$.

Tabel 4. Hubungan anemia dengan persalinan prematur

\begin{tabular}{ccccc}
\hline & \multicolumn{2}{c}{$\begin{array}{c}\text { Persalinan } \\
\text { prematur }\end{array}$} & Jumlah & \\
\cline { 2 - 4 } Anemiannnn & $\begin{array}{c}\text { Ya } \\
(\boldsymbol{\%})\end{array}$ & $\begin{array}{c}\text { Tidak } \\
(\boldsymbol{\%})\end{array}$ & $(\boldsymbol{\%})$ & $\boldsymbol{p}$ \\
\hline \multirow{2}{*}{ Ya } & 21 & 32 & 53 & \\
& $(39,6)$ & $(60,4)$ & $(100,0)$ & \\
Tidak & 16 & 99 & 115 & 0,000 \\
& $(13,9)$ & $(86,1)$ & $(100,0)$ & \\
Jumlah & 37 & 131 & 168 & \\
& $(22,0)$ & $(78,0)$ & $(100,0)$ & \\
\hline
\end{tabular}

Tabel 4 menunjukkan ibu yang mengalami persalinan prematur dengan anemia sebanyak 21 orang $(39,6 \%)$, yang tidak anemia sebanyak 16 orang $(13,9 \%)$. Analisis chi-square pada variabel diatas menunjukkan nilai $p<0,05$, yaitu nilai $p=$
0,000. Hasil ini menunjukkan terdapat hubungan yang sangat bermakna antara anemia pada ibu hamil dengan kejadian persalinan prematur.

\section{BAHASAN}

Berdasarkan karakteristik sampel menurut usia pada tabel 1 didapatkan usia ibu yang bersalin di RSUP Prof. Dr. R. D. Manado sebagian besar pada usia 21-34 tahun yaitu 104 orang $(61,9 \%)$. Menurut penelitian, usia reproduktif yang optimal untuk reproduksi sehat adalah antara 20-35 tahun. Risiko meningkat ada usia $<20$ tahun maupun $>35$ tahun. Ibu dengan usia muda juga memiliki risiko anak yang dilahirkan prematur. $^{10}$

Pada tabel 2 terlihat bahwa ibu yang bersalin di RSUP Prof. Dr. R. D. Kandou Manado yang tidak anemia sebanyak 115 orang $(70,6 \%)$ merupakan yang terbanyak, anemia sedang sebanyak 30 orang $(17,9 \%)$, anemia ringan sebanyak 22 orang $(13,1 \%)$ dan yang paling sedikit anemia berat 1 orang $(0,6 \%)$. Hal ini menunjukkan sebagian besar ibu tidak mengalami anemia selama kehamilan. Hal ini dapat dihubungkan dengan keteraturan ibu dalam melakukan ANC selama kehamilan, dimana pada penelitian ini sebagian besar ibu melakukan ANC >4 kali yaitu sebanyak 119 orang $(70,8 \%)$. Sesuai dengan penelitian yang dilakukan oleh Fatimah ${ }^{11}$ yang menyatakan bahwa semakin teratur ibu melakukan ANC maka ibu hamil tidak akan mengalami anemia.

Wanita anemia lebih sering di jumpai dalam kehamilan. Dimana berdasarkan penelitian terjadi perubahan konsentrasi Hemoglobin sesuai dengan bertambahnya usia kehamilan. Hal ini disebabkan karena dalam kehamilan, kebutuhan oksigen lebih tinggi, sehingga memicu eritropoientin. Akibatnya, volume plasma bertambah dan sel darah merah (eritrosit) meningkat. Namun peningkatan volume plasma terjadi dalam proporsi yang lebih besar jika dibandingkan dengan peningkatan eritrosit sehingga terjadi penurunan konsentrasi hemoglobin $(\mathrm{Hb})$ akibat hemodelusi. Ekspansi volume plasma ini merupakan 
penyebab anemia fisiologik pada kehamilan. $^{12}$ Teori diatas sesuai hasil penelitian yang dilakukan oleh Saifudin, di mana ibu masih banyak yang mengalami anemia pada kehamilan yaitu sebanyak $39,5 \%$ ibu hamil. ${ }^{13}$

Berdasarkan Tabel 3 ibu yang bersalin di RSUP Prof. Dr. R. D. Kandou Manado dengan persalinan aterm yaitu sebanyak 131 orang $(78,0 \%)$ sedangkan ibu dengan persalinan prematur yaitu sebanyak 37 orang $(22,0 \%)$. Hal tersebut menunjukkan bahwa sebagian besar ibu hamil di RSUP Prof. Dr. R. D. Kandou Manado dengan persalinan aterm. Hal ini disebabkan karena sebagian besar sampel ibu hamil yang bersalin tidak mengalami anemia selama kehamilannya.

Berdasarkan Tabel 4 Ibu dengan persalinan prematur yaitu sebanyak 37 orang $(22,0 \%)$, dimana yang mengalami anemia selama kehamilan adalah yang terbanyak yaitu 21 orang $(39,6 \%)$ dan yang tidak mengalami anemia yaitu sebanyak 16 orang $(13,9 \%)$. Hasil analisis uji chi-square menunjukkan bahwa terdapat hubungan bermakna antara anemia pada ibu saat kehamilan dengan kejadian persalinan prematur dengan nilai signifikansi $p<0,05$ yaitu nilai $p=0,000$. Hal ini sesuai dengan penelitian oleh Sriwahyuni ${ }^{14}$ dimana terdapat hubungan yang bermakna antara anemia pada ibu hamil dengan kejadian persalinan prematur (nilai $p=0,007$ ). Penelitian yang dilakukan oleh Zhang ${ }^{15}$ dengan studi kohort prospektif didapatkan hubungan bermakna antara anemia dengan kejadian persalinan prematur. Hasil penelitian yang dilakukan oleh Irmawati $^{8}$ menunjukkan bahwa ibu hamil dengan anemia berisiko sebesar empat kali untuk melahirkan prematur dibandingkan dengan ibu yang tidak mengalami anemia selama kehamilannya.

Klebenoff $^{16}$ juga mempelajari lebih dari 27.000 wanita dan mendapatkan peningkatan risiko persalinan prematur pada anemia midtrimester. Hal ini berkaitan dengan peningkatan risiko infeksi dan hipoksia kronis yang dapat menginduksi stress pada maternal dan janin. Respon stres ini memicu pelepasan hormon kortisol. Kortisol akan mengaktifkan aksis hipotalamus-hipofisis-adrenal maternal ataupun janin. ${ }^{15}$ Melalui aksis hipotalamus-hipofisis-adrenal janin, maka Corticotropin Releasing Hormon (CRH) akan terbentuk lebih banyak. CRH memegang peranan dalam jalur persalinan secara umum. Mekanisme $\mathrm{CRH}$ dalam memicu persalinan yaitu: meningkatkan prostaglandin $\mathrm{E}_{2} \quad\left(\mathrm{PGE}_{2}\right)$, meningkatkan prostaglandin $2 a(\mathrm{PG} 2 \mathrm{a})$, stimulasi adrenokortikotropin (ACTH), serta menginduksi adrenal janin untuk membentuk DHEAS. Semua mekanisme ini akan menyebabkan pendataran serviks, kontraksi miometrium, sehingga akan menginduksi persalinan prematur.

\section{SIMPULAN}

Berdasarkan hasil penelitian dapat disimpulkan bahwa terdapat hubungan yang bermakna antara anemia pada ibu hamil dengan kejadian persalinan prematur.

\section{SARAN}

Bagi petugas kesehatan baik perawat, bidan dan dokter agar lebih meningkatkan promosi dan penyuluhan kesehatan tentang dampak anemia pada kehamilan.

Bagi Ibu agar dapat melakukan kunjungan kehamilan secara rutin, mengkonsumsi makanan yang bergizi serta suplementasi zat besi untuk mencegah anemia selama kehamilan dan bila diperluakan dapat melakukan pemeriksaan ulang kadar hematokrit atau hemoglobin untuk mendeteksi adanya penurunan signifikan.

\section{DAFTAR PUSTAKA}

1. Centers for Disease Control and Prevention (CDC) 2007. Birth: Final data for 2005. [diakses 07 November 2016]. Tersedia pada :http://www.cdc.gov/nchs/data/nvsr56 _06.pdf.

2. Drife $\mathbf{J}$, Mogawan BA. Clinical obstetric and gynecology: prematurity. London: Saunders; 2004. h.375-80.

3. Stacy B, Wodjdyla D, Say L, Betran A, Merialdi M, Rubens C, et al. The 
worldwide incidense of preterm birth: a systematic review of maternal and morbidity. Bull World Health Organ. 2010;88:31-8.

4. The Sea-Orchid Study Group. Use of evidence-based practices in pregnancy and childbirth: south east asia optimising reproductive and child health in developing countries project. Plos One. 2008;3:1-6.

5. Mocthar AB. Persalinan prematur. Dalam: Saifddin AB, Rachimhadhi T, Wiknjosastro GH. Ilmu Kebidanan. Edisi ke-4. Jakarta: Yayasan Bina Pustaka Sarwono Prawirohardjo; 2014. Hal.667-76.

6. Ren A, Wang J, Ye R, Lis, Liu J, LiZ. Low first-trimester hemoglobin and low birth weight, preterm birth and small for gestasional age newborn. Int J Gynecol Obstet. 2007;98:124-28.

7. World Health Organization. The prevalency of anemia in women: a tabulation of available information. Edisi ke-2. Geneva: World Health Organization; 1992.

8. Irmawati. Pengaruh anemia ibu hamil dengan terjadinya persalinan prematur di rumah sakit ibu dan anak budi kemuliaan jakarta. Tesis FKM UI. Jakarta; 2010.

9. Rahmawati. Faktor-faktor yang mempengaruhi terjadinya persalinan preterm. 29 Januari 2013 (diakses 07
November 2016). Tersedia pada : http://eprints.ums.ac.id/24128/10/NA SKAH_PUBLIKASI.pdf.

10.Kidanto HL, Mogren I, Lindmark G, et. al. Risk for preterm delivery and low birth weight are independently increased by severity of maternal anemia. S Afr Med J. 2009;99(2):98.

11.Fatimah, Ernawati S. Pelaksanaan antenatal care berhubungan dengan anemia pada kehamilan trimester III. JNKI. 2015;3:134-9.

12.Abdulmuthalib. Kelainan hematologik. Dalam: Saifuddin AB, Rachimhadhi T, Wiknjosastro GH. Ilmu Kebidanan. Edisi ke-4. Jakarta: Yayasan Bina Pustaka Sarwono Prawirohardjo; 2014. hal.774-99.

13.Saifudin M, Anjelina AD. Hubungan antara paritas dengan kejadian anemia pada kehamilan. Surya. 2008;1:102-7.

14. Wahyuni S. Hubungan anemia dengan kejadian persalinan prematur. Involusi Kebidanan. 2011;1:1-10.

15.Zhang Q, Ananth CV, Li Z, Smulian JC. Maternal anema and preterm birth: a prospective cohort study. International Journal of Epidemiology. 2009; 1381-9.

16.Cunningham FG, Lenovo KJ, Bloom, SL, Hauth JC, Rouse DJ, Spong CY. Obstetri williams. Edisi ke-23. Jakarta: EGC.; 2013. h. 846-76. 